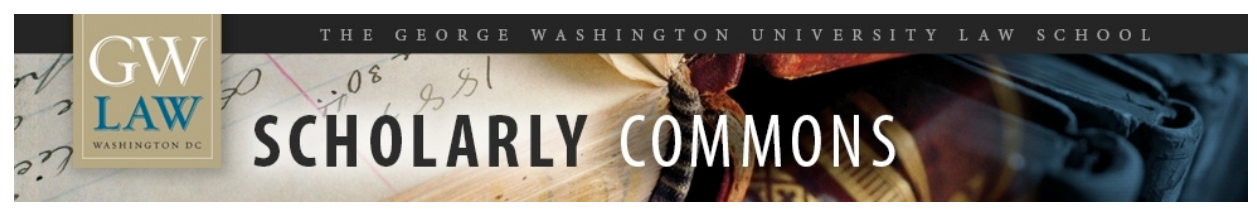

\title{
Screening Legal Claims Based on Third-Party Litigation Finance Agreements and Other Signals of Quality
}

\author{
Michael B. Abramowicz \\ George Washington University Law School, abramowicz@law.gwu.edu \\ Omer Alper \\ The Johns Hopkins University
}

Follow this and additional works at: https://scholarship.law.gwu.edu/faculty_publications

Part of the Law Commons

\section{Recommended Citation}

Abramowicz, Michael B., Screening Legal Claims Based on Third-Party Litigation Finance Agreements and Other Signals of Quality (2013). Screening Legal Claims Based on Third-Party Litigation Finance Agreements and Other Signals of Quality, 66 Vand. L. Rev. 1641 (2013) (symposium contribution, with Omer Alper). ; GWU Law School Public Law Research Paper No. 2019-19; GWU Legal Studies Research Paper No. 2019-19. Available at SSRN: https://ssrn.com/abstract=3366641

This Article is brought to you for free and open access by the Faculty Scholarship at Scholarly Commons. It has been accepted for inclusion in GW Law Faculty Publications \& Other Works by an authorized administrator of Scholarly Commons. For more information, please contact spagel@law.gwu.edu. 


\title{
Screening Legal Claims Based on Third-Party Litigation Finance Agreements and Other Signals of Quality
}

\author{
Michael Abramowicz* \\ Omer Alper**
}

II. MATHEMATICAL MODEL ............................................. 1648

A. An Illustration ............................................ 1649

B. $\quad$ A Model Without Trial Costs .............................. 1653

C. $\quad$ A Model with Trial Costs.................................... 1658

III. SIMULATION MODEL ................................................ 1662

A. Change in Signal Strength ............................. 1665

B. $\quad$ Trial Costs ........................................................ 1667

C. Majoritarian Correctness.............................. 1668

D. Costliness of the Signal ................................. 1669

IV. CONCLUSION........................................................ 1670

V. APPENDIX ............................................................ 1673

\section{INTRODUCTION}

The advent of third-party litigation finance introduces a new gatekeeper to the legal process. Before deciding to lend money to a plaintiff, a litigation finance company will conduct at least some review and make an assessment of the quality of the case. ${ }^{1}$ Since

\footnotetext{
* Professor, George Washington University Law School. J.D., Yale Law School; B.A., Amherst College.

** Principal Research Scientist, CNA. Ph.D., Johns Hopkins University; B.A., Princeton University.

1. See generally Nicholas Dietsch, Litigation Financing in the U.S., the U.K., and Australia: How the Industry Has Evolved in Three Countries, 38 N. KY. L. REV. 687, 687-88 (2011) (providing an overview of how litigation finance works).
} 
litigation finance loans are generally nonrecourse,$^{2}$ a litigation finance company is likely to refuse to loan money to plaintiffs with the weakest cases. Such voluntary claim screening may improve social welfare by reducing the incidence of frivolous claims. But the volume of frivolous claims may still be higher than it would be in a world without third-party litigation finance. In particular, third-party litigation finance companies, which lend money to litigants to enable them to pursue cases, might sometimes finance claims that would have a very low probability of prevailing at trial on the assumption that such claims may encourage nuisance settlements. ${ }^{3}$ This danger may be greater than when a plaintiff self-finances, because the provision of outside financing may help make credible a threat to proceed to trial in the absence of a settlement. ${ }^{4}$ This possibility makes the social welfare consequences of alternative litigation finance an empirical question. Surely, many financed claims will be meritorious, in the probabilistic sense that if the plaintiffs were to receive financing, they would be more likely than not to win at trial. It is uncertain, however, whether the beneficial economic effects of enabling such claims outweigh the negative effects of facilitating claims that courts are highly likely to reject. The answer may vary based on the type of claim or the type of litigation finance arrangement.

2. See Courtney R. Barksdale, Note, All That Glitters Isn't Gold: Analyzing the Costs and Benefits of Litigation Finance, 26 REV. LITIG. 707, 708-09 n.8 (2007) (quoting litigation finance contracts provisions guaranteeing that loans are nonrecourse, meaning that they are not secured by other assets).

3. See Jeremy Kidd, To Fund or Not to Fund: The Need for Second-Best Solutions to the Litigation Finance Dilemma, 8 J.L. ECON. \& POL’Y 613, 627-29 (2012) (discussing how rational, self-interested financiers would invest in a frivolous lawsuit because there is a "chance that a claim will slip through" and lead to a settlement offer); Geoffrey J. Lysaught \& D. Scott Hazelgrove, Economic Implications of Third-Party Litigation Financing on the U.S. Civil Justice System, 8 J.L. ECON. \& POL'Y 645, 662-65 (2012) (explaining how an increase in the supply of third-party financing may contribute to increases in speculative litigation on the margin). But see Mariel Rodak, Comment, It's About Time: A Systems Thinking Analysis of the Litigation Finance Industry and Its Effect on Settlement, 155 U. PA. L. REV. 503, 518-19 (2006) (providing a rebuttal to assertions that the litigation finance industry promotes frivolous litigation). In a nascent litigation finance industry, it is unlikely that many cases will be frivolous because the earliest recipients of funding are likely to be those with the strongest cases. But as the industry grows, the danger will become more serious.

4. A provision of outside funding can be a mechanism by which a plaintiff "ties its hands." See generally Bruce L. Hay, Procedural Justice-Ex Ante vs. Ex Post, 44 UCLA L. REV. 1803, 1811 (1997) (describing how litigants might face conflict between their ex ante and ex post preferences). If the defendant knows that the plaintiff does not care about the cost of trial, then it may offer more advantageous settlement offers. Thus, the litigation finance company may agree to contracts generously assuring plaintiffs continued funding because the company and the plaintiff share in the benefits of the increased credibility. 
Although unregulated third-party financing might lead to more nuisance claims, a regulated system could be structured to block the financing of many nuisance claims without also blocking stronger claims. The legal system might use accumulated empirical evidence to make case-by-case estimates of case quality and bar financing in cases in which the measure of case quality is below some predetermined threshold. These case-by-case estimates would depend on the area of law, the specific attributes of the claim, and the terms of the proposed litigation financing arrangement, with higher interest rates signaling a relatively weak claim. If detailed regression data were available, a statistical formula could be devised that would assign a preliminary estimate of the probability that the claim would prevail. Under this system, the law would provide that claims below a certain probability threshold could proceed only in the absence of litigation financing.

Even absent a sufficient amount of data to conduct regression studies, one could devise legal rules that take advantage of the finance company's expertise in separating relatively strong claims from relatively weak ones. For example, the law could allow litigation financing, but only if the finance company and the defendant agree that the loser will pay the winner's costs. ${ }^{5}$ Then, the litigation finance company would be on the hook for the other side's fees if it loses at trial; however, if its client prevails, then the finance company would be refunded whatever money it spent on the litigation, plus interest payments from its client. A litigation finance company would only agree to such a regime if it is sufficiently confident in its client's claims. The demonstration of a company's faith in the merits of its client's claims, combined with the tendency of fee-shifting rules to increase the cost of litigation, ${ }^{6}$ might lead many defendants to decline the loser-pays option. Regardless, the mere possibility of such fee shifting might help separate strong and weak claims. A weaker version of this rule would require the loser to pay only some fraction of the winner's costs; a stronger version would require the loser to pay a multiple of the winner's costs. ${ }^{7}$ The degree of claim screening will

5. In general, parties do not opt into or out of fee-shifting rules. See John J. Donohue III, Opting for the British Rule, or if Posner and Shavell Can't Remember the Coase Theorem, Who Will?, 104 HARV. L. REV. 1093, 1093-95 (1991) (discussing the differences between the British rule and American rule for fee shifting). A legal rule explicitly requiring a party to offer to opt into the British rule would, however, likely change this since the other party would not believe that the offering party was suggesting the British rule for personal advantage.

6. See, e.g., Avery Katz, Measuring the Demand for Litigation: Is the English Rule Really Cheaper?, 3 J.L. ECON. \& ORG. 143, 144 (1987) (suggesting that a change to the English rule would increase the amount expended per lawsuit).

7. The fee-shifting literature has recognized that even if it is desirable that the losing party make a payment to the winning party, the optimal amount of money that the losing party 
increase as the fraction or multiple increases. ${ }^{8}$ Fee shifting thus provides a flexible mechanism that can be adjusted based on the amount of gatekeeping desired.

We suggest that the legal system allow some claims to proceed and bar others based on signals of litigation quality gleaned from third-party assessments. This proposal may seem radical. These thirdparty assessments are based on information about the quality of the claim that is preliminary and extrajudicial. Thus, the legal system would be allowing some claims to proceed and barring others based on a very noisy signal of claim quality, rather than on some form of adjudication. In this article, we take on the objection that the legal system should not use proxies in this manner. We argue that whenever the legal system has some signal of the quality of a plaintiff's case, even if the signal is a noisy one, there is some estimated level below which the legal system should block the claim through a procedure akin to summary judgment. We also show that there is some level above which the legal system should block a defense of this claim. Our arguments apply to all signals of claim quality, not just the signals that arise from litigation finance. But the argument is particularly relevant in the context of litigation finance for two reasons: First, litigation finance necessarily introduces a gatekeeper into the litigation process. Second, because restrictions on litigation finance already exist, rules limiting litigation finance-for example, the aforementioned rule requiring a fee-shifting arrangement-seem unlikely to offend due process. Other potential applications of our argument would be much more likely to encounter due process objections, especially in the United States.

Our approach of using a gatekeeper to discourage frivolous claims differs in a significant way from the existing economic literature. Authors who propose mechanisms to discourage unmeritorious suits (and unmeritorious defenses of suits) have

should pay to the winning party might differ from the amount of legal fees. See A. Mitchell Polinsky \& Daniel L. Rubinfeld, Optimal Awards and Penalties When the Probability of Prevailing Varies Among Plaintiffs, 27 RAND J. ECON. 269, 277 (1996) (noting that neither "the implicit award nor the implicit penalty under the British rule necessarily corresponds closely to the optimal award and penalty").

8. If the litigation finance company were certain of winning should the case go to trial, then it would be guaranteed to receive its reasonable fees, and it would accept a case at an interest rate sufficient only to compensate it for the discounted value of its time. At lower levels of confidence, whether the litigation finance company would take a case would depend on the interest rate on the probability that the defendant would agree to fee shifting and on the magnitude of fee shifting. It is beyond the scope of this Article to calculate the optimal fraction or multiple. The point is that at any given fraction or multiple, a litigation finance company would provide a signal of its confidence in the litigation. 
generally focused on imposing penalties after suits are resolved. For example, under Polinsky and Rubinfeld's model, ${ }^{9}$ courts would determine whether to impose sanctions for a frivolous suit only after the underlying proceeding has concluded. Similarly, the British Rule for attorneys' fees is often called the "loser pays" rule because any fee shifting depends on the outcome of the lawsuit. ${ }^{10}$ An exception in the literature is the "sincerity rule" proposed by David Anderson. ${ }^{11}$ Under this rule, a party may give the other a take-it-or-leave-it settlement offer, and if the other side declines, the offeror must pay the other party's trial costs. Because settlement will be completely prohibited later, the offeree will accept the offer if it is greater than what the offeree expects to receive at trial. Even this mechanism, however, does not take into account any information from third-party assessments about the strength of the suit.

This Article proposes screening legal claims based on ex ante assessments of lawsuit quality. Under claim screening, if an ex ante signal indicates that a plaintiff's probability of success is sufficiently low, the plaintiff will not be permitted to bring the claim. We label this "pro-defendant screening," but we also consider "pro-plaintiff screening." Under pro-plaintiff screening, if the ex ante signal indicates that a plaintiff's probability of success is sufficiently high, the defendant is not permitted to defend the claim.

This proposal does not depend on trial costs; however, as we will show, the case for it is strengthened when litigation is expensive. Rather, the argument is based on a core trade-off. On one hand, reliance on a noisy signal sacrifices potentially better information that may develop at trial. On the other hand, trials are generally one-shot affairs. It is not feasible to repeat a trial many times, with different judges and juries; thus, a trial reveals only what a particular judge and jury decided, not what most would decide. When a signal suggests that the plaintiff's estimated probability of victory is very small, the danger that the signal is inaccurate may be less than the danger that a single trial will result in an idiosyncratic outcome. Even if trials

9. See A. Mitchell Polinsky \& Daniel L. Rubinfeld, Sanctioning Frivolous Suits: An Economic Analysis, 82 GEO. L.J. 397, 404 (1993) (describing the frivolous-suit model).

10. See, e.g., Steven Shavell, Suit and Settlement vs. Trial: A Theoretical Analysis Under Alternative Methods for the Allocation of Legal Costs, 11 J. LEGAL STUD. 55, 55 (1982) (describing the British system whereby the losing side bears all costs). Even Professors Bebchuck and Chang's innovative formulation would shift fees only when the margin of victory is sufficiently large, fee shifting depends on the trial outcome. See Lucian Arye Bebchuk \& Howard F. Chang, An Analysis of Fee-Shifting Based on the Margin of Victory: On Frivolous Suits, Meritorious Suits, and the Role of Rule 11, 25 J. LEGAL STUD. 371, 396 (1996).

11. David A. Anderson, Improving Settlement Devices: Rule 68 and Beyond, 23 J. LEGAL STUD. 225, 240-41 (1994) (defining the "sincerity rule"). 
were costless, automatic resolution of the lawsuit would be preferable to a one-shot trial if the signals were sufficiently extreme. When the signal value is closer to the center of the probability continuum, however, a trial is preferable.

A claim-screening device can also be valuable when it causes litigation to be settled preemptively. In the absence of pro-defendant claim screening, for example, plaintiffs might sometimes bring suits with a low probability of victory, either because damages are sufficiently high to make the suits valuable, or because the expectation of extracting a settlement makes the suits worthwhile despite their negative expected value. ${ }^{12}$ A claim-screening device would reduce plaintiffs' incentives to bring and maintain such suits or encourage plaintiffs to settle such suits for even smaller amounts. A defendant ordinarily might be willing to pay $\$ 5$ million to settle a claim from a plaintiff who has a $5 \%$ chance of winning $\$ 100$ million, but perhaps not if the claim-screening mechanism will prevent the claim from going to trial anyway. Thus, claim screening may be desirable even if it affects only those cases that would most likely settle anyway. ${ }^{13}$

Our results reinforce the value of forcing or encouraging all-ornothing rather than compromise resolutions to lawsuits. David Kaye defended the preponderance-of-the-evidence standard on similar grounds against an alternative that would allow damages based on the probability of victory. ${ }^{14}$ If the probability that a defendant will be found liable is 0.75 , then the preponderance-of-the-evidence standard would provide $100 \%$ damages while a probabilistic approach would provide $75 \%$ damages. The question is thus whether it is efficient to grant the additional $25 \%$ in damages, and Kaye's point is that there is a 0.75 probability that these additional damages are justified. Kaye

12. For an assessment of why plaintiffs might bring negative-expected-value suits, see Robert G. Bone, Modeling Frivolous Suits, 145 U. PA. L. REv. 519, 537-42 (1997).

13. Low-probability cases are particularly likely to settle when the actual probability of a plaintiff's success is near an end of the probability continuum because it is less likely that the estimates of the probability of victory will be sufficiently asymmetric to justify going to trial. Donohue, for example, conjectures that suits will generally go to trial only if the plaintiff's and defendant's estimates of the probability of victory differ by more than 0.50 . See John J. Donohue III, The Effects of Fee Shifting on the Settlement Rate: Theoretical Observations on Costs, Conflicts, and Contingency Fees, 54 LAW \& ConTEMP. ProBs. 195, 204-05 (1991) (detailing the significance of the 0.5 value). This is more likely if the actual probability is in the middle of the probability spectrum than if the actual probability is near the ends, for example 0.05 or 0.95 . See $i d$.

14. See David Kaye, The Limits of the Preponderance of the Evidence Standard: Justifiably Naked Statistical Evidence and Multiple Causation, 1982 AM. B. FounD. RES. J. 487, 502 (analogizing the rule to maximum likelihood, which "makes a few expensive mistakes, but it does not err at all in most cases"). 
concludes that the optimal damages function is discontinuous, with no damages for a perceived probability of liability below 0.5 and full damages for everything else. Although Kaye focused on damage awards at trial, the same logic applies to settlements in the shadow of a trial. Indeed, assuming that the vast majority of cases settle, Kaye's system will accomplish little. If the probability that a defendant will be found liable approximates the probability that a defendant should be found liable, then settlement amounts will resemble the outcomes that would occur in a proportional damages regime. For example, if $60 \%$ of courts would find a defendant liable and there is roughly a $60 \%$ chance that the defendant should be found liable, then Kaye would recommend $100 \%$ damages, but settlement would likely result in compromise. Claim screening provides an antidote, pushing in the direction of all-or-nothing results. In the analysis that follows, claim screening applies to suits at the time of filing or shortly thereafter. Of course, if universal claim screening were thought too expensive, it could be applied shortly before trial. Then, as long as claim screening is sufficiently cheaper than trial, overall costs will likely be reduced. The anticipation of such claim screening would still deter some frivolous suits and defenses, though we expect that the benefits of claim screening would be reduced as well.

The argument proceeds as follows. In Part II.A, we offer a simple mathematical model. Initially, the analysis assumes that the number of truly liable and truly not liable cases are equal, and that false positives are as costly as false negatives. Under this assumption (among others), there exists some threshold signal value below which social welfare will be raised by barring plaintiffs' suits, and some other threshold above which social welfare will be raised by automatically resolving the liability issue in favor of the plaintiff. Even if this assumption is relaxed, one-sided claim screening will still be useful. We show in Part II.B that our conclusions are only strengthened once trial costs are factored in. The higher the trial costs, the closer the optimal thresholds for claim screening will be to the middle of the probability distribution.

To obtain a better appreciation for plausible values of these thresholds given different signal strengths and to incorporate the dynamics of settlement into our analysis, we offer a simulation model in Part III. The simulation suggests that, under plausible assumptions, the optimal thresholds for claim screening are surprisingly close to 0.50 . We show that this result is robust to a variety of changes in assumptions. For example, the 0.50 threshold is optimal whether the third-party signal is strong or quite weak, whether the parties are relatively good or bad at estimating the 
strength of the claim, and whether one party has better information than another. Lowering or raising the parties' trial costs, even if that creates asymmetric trial costs, does not alter this conclusion. The most important question may be how costly the signal is to obtain; however, claim screening may well be economical as long as it is cheaper than the trials that it will sometimes replace. When the plaintiff opts for litigation financing, the finance companies will perform a gatekeeping function anyway, and screening should not pose a significant additional cost.

We believe that these results will tend to understate the value of claim screening for two reasons. First, we suspect that there are many more low-probability claims than claims near the middle of the probability distribution. It is easier to develop legal theories that have only a small chance of prevailing than to develop successful legal theories. Lawyers should prefer strong cases to weak ones, all else being equal, but the existing legal system may encourage the filing of low-probability "strike suits" with high damage claims in the hope of settlement. Empirical evidence supports the notion that such suits (e.g., derivative actions) usually fail when tried. ${ }^{15}$ Second, our results use a fixed pool of cases. But if our approach increases litigation accuracy, then parties may improve their behavior in response, reducing the probability of litigation and changing the pool of cases. For example, defendants may be more likely to take efficient precautions if legal accuracy increases. ${ }^{16}$ We do not explicitly model this. Our approach is general across litigation and not limited to the context of torts; we do not wish to limit the analysis by focusing only on areas of law in which the court assesses whether the defendant has taken sufficient precautions.

\section{MATHEMATICAL MODEL}

Consider a set of cases where the correct finding is either liability or no liability. Suppose for any given case that we do not observe the correct finding ex ante but receive a signal of the proportion of judges who would assign liability. If judges are more likely to be right than wrong over the set of all cases, we should employ claim screening rather than traditional adjudication in cases with a sufficiently strong signal. To appreciate this intuition, consider

15. See Roberta Romano, The Shareholder Suit: Litigation Without Foundation?, 7 J.L. ECON. \& ORG. 55, 60 (1991) (finding that shareholder plaintiffs have "abysmal success in court").

16. See Louis Kaplow \& Steven Shavell, Accuracy in the Determination of Liability, 37 J.L. \& ECON. 1, 2-3 (1994) (describing how higher levels of accuracy will increase deterrence). 
two extreme possibilities: a perfect signal and a signal containing no information at all. With the perfect signal, adjudication is worthless because the signal reveals the majority of judges' decisions and, consequently, the true merit of the case (under our assumptions of aggregate judicial accuracy). For example, suppose a signal indicates with certainty that $75 \%$ of judges would impose liability after hearing all the evidence. This implies that the correct decision is to impose liability, and relying on this perfect signal to find automatic liability would lead to the correct resolution. Adjudication would introduce an unnecessary $25 \%$ risk of an incorrect resolution. On the other hand, a signal containing no information at all (such as a coin flip) is worthless. Relying on it would produce only a 50\% chance of arriving at the correct answer. Since judges are right more than they are wrong, adjudication can do better than this.

\section{A. An Illustration}

Figure 1 provides an illustration of claim screening's potential benefits and costs for defendants, reflecting the intuition and structure of our formal model. Figure 1 illustrates a particular set of cases. In each case, the correct finding is either "liability" (denoted $\bar{L}$ ) or "no liability" (denoted $\overline{N L}$ ). However, since judges estimate $\bar{L}$ and $\overline{N L}$ with error, we use $L$ and $N L$ to denote the actual resolution of the cases.

$F_{N L \mid \overline{N L}}(s)$ denotes an arbitrarily defined cumulative distribution function ("CDF") of signal values $s$ for cases in which the correct finding is not liability. Thus, $F_{N L \mid \overline{N L}}(s)$ is the proportion of truly not liable cases that would automatically (and correctly) be dismissed under a claim screening mechanism if the threshold for automatic dismissal were set at $s$. Similarly, $F_{N L \mid \bar{L}}(s)$ denotes a CDF of signal values for false-negative cases, truly liable cases that would automatically be dismissed under a claim-screening mechanism given a threshold of $s$. Thus, it represents the proportion of false negatives. In this illustration, $F_{N L \mid \overline{N L}}(s)$ is strictly above $F_{N L \mid \bar{L}}(s)$. This reflects the intuition that, even if the signal is somewhat noisy, truly not liable cases are more likely to produce low signals than truly liable cases. The curves meet at 0 and 1 because, if the thresholds were set at these extremes, either none or all of the cases-both the truly not liable and truly liable cases-would be dismissed automatically. 


\section{Figure 1: Pro-Defendant Claim Screening}

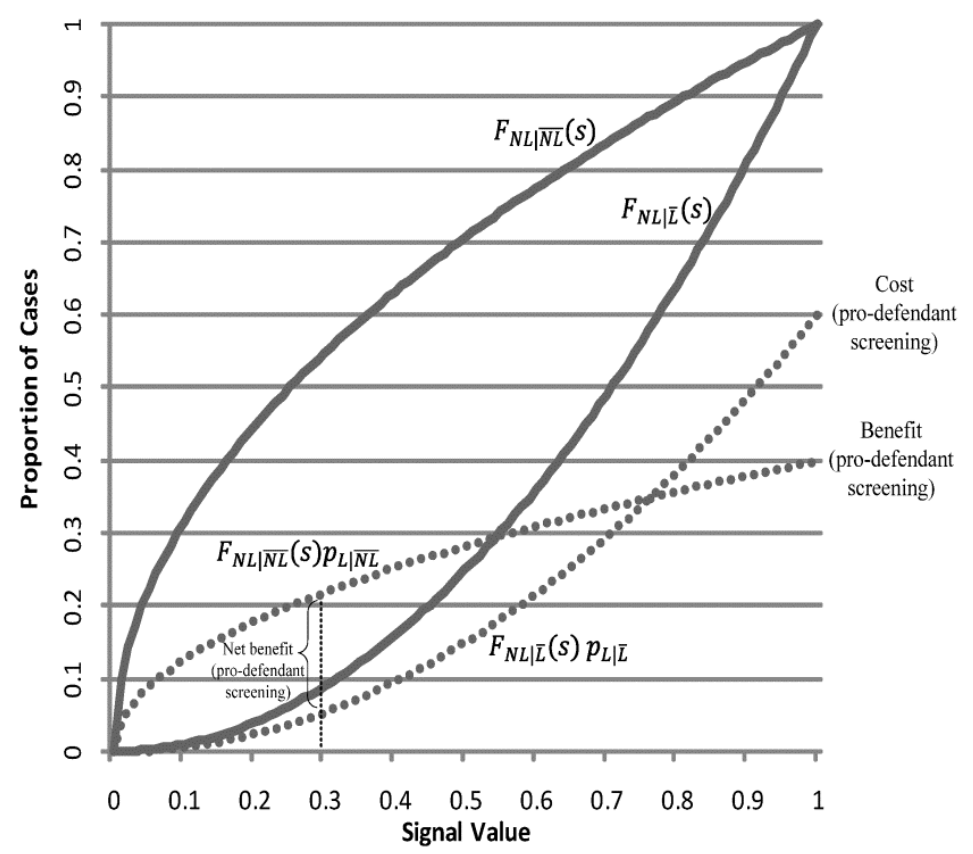

To measure the benefits and costs of claim screening for the hypothetical set of cases in the illustration, we must consider how these cases would be resolved in the status quo absent claim screening. We use $p_{L \mid \bar{L}}$ to represent the probability that liability would be found in a truly liable case, and $p_{L \mid \overline{N L}}$ represents the probability that liability would be found in a truly not liable case. In the illustration, $p_{L \mid \bar{L}}>p_{L \mid \overline{N L}}$ and are invariant to $s$ (for simplicity). The dashed lines represent the respective CDFs multiplied by the corresponding trial outcome. Thus, $F_{N L \mid \overline{N L}}(s) p_{L \mid \overline{N L}}$ represents the proportion of truly not liable cases that would automatically (and correctly) be dismissed under a claim-screening mechanism if the threshold for automatic dismissal were set at $s$ but that would have resulted in an incorrect finding of liability in the absence of claim screening. Similarly, $F_{N L \mid \bar{L}}(s) p_{L \mid \bar{L}}$ represents the proportion of truly liable cases that would automatically (and incorrectly) be dismissed under a claim-screening mechanism if the threshold for automatic dismissal were set at $s$ and that would have correctly resulted in a finding of liability in the absence of claim screening.

These curves thus represent the benefit and the cost of claim screening, respectively. The benefit of claim screening is that it reduces the number of false liability findings. Accordingly, $F_{N L \mid \overline{N L}}$ 
(s) $p_{L \mid \overline{N L}}$ signifies the cases resolved correctly under claim screening but incorrectly under the status quo. The cost of claim screening is that it reduces the number of correct liability findings. $F_{N L \mid \bar{L}}(s) p_{L \mid \bar{L}}$ captures this cost by showing the cases resolved incorrectly under claim screening but correctly under the status quo. The heights of the curves illustrate the benefits and costs for particular signal thresholds for pro-defendant claim screening. That threshold is set at 0.30 (which is where the slopes of the dotted lines are equal and thus the optimal value for the set of cases illustrated in Figure 1). The amount $F_{N L \mid \overline{N L}}$ $(s) p_{L \mid \overline{N L}}$ represents the benefits of pro-defendant claim screening (reduced false positives). The amount $F_{N L \mid \bar{L}}(s) p_{L \mid \bar{L}}$ represents the costs of pro-defendant claim screening (increased false negatives). The difference between the heights of these two curves represents the net benefit of pro-defendant claim screening, and the optimal threshold occurs where this net benefit is maximized.

Figure 2 extends Figure 1 to illustrate the potential benefits of pro-plaintiff claim screening for the same set of cases, where the plaintiff automatically wins if a signal exceeds a particular value. We define $F_{L \mid \bar{L}}(s)=1-F_{N L \mid \bar{L}}(s)$, and we define $F_{L \mid \overline{N L}}(s)=1-F_{N L \mid \overline{N L}}(s)$. Thus, $F_{L \mid \bar{L}}(s)$ represents the proportion of the truly liable cases that would result in an automatic liability determination if the threshold for pro-plaintiff screening were set at $s$, and $F_{L \mid \overline{N L}}(s)$ represents the corresponding proportion of the truly not liable cases. We then define $p_{N L \mid \bar{L}}=1-p_{L \mid \bar{L}}$ and $p_{N L \mid \overline{N L}}=1-p_{L \mid \overline{N L}}$. Note that $F_{L \mid \bar{L}}(s)$ is above $F_{L \mid \overline{N L}}(s)$ because the truly liable cases will generally produce higher signal values. 
Figure 2: Pro-Defendant and Pro-Plaintiff Claim Screening

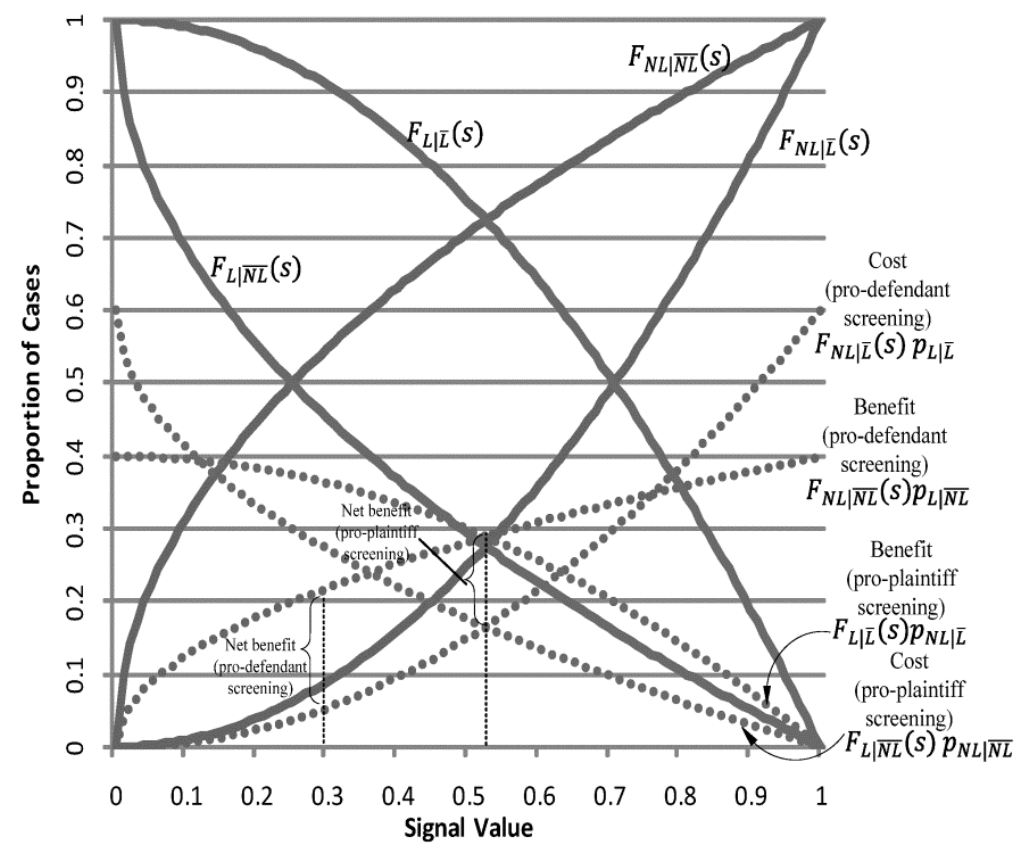

The dotted lines represent the benefit and cost of pro-plaintiff claim screening. $F_{L \mid \bar{L}}(s) p_{N L \mid \bar{L}}$ represents the truly liable cases that will be resolved automatically (and correctly) for the plaintiff under pro-plaintiff screening but would have been resolved incorrectly in court, and $F_{L \mid \overline{N L}}(s) p_{N L \mid \overline{N L}}$ represents the truly not liable cases that will be resolved automatically (and incorrectly) for the plaintiff but would have been resolved correctly in court. The heights of the red dotted lines thus represent the benefit (reduced false negatives) and the cost (increased false positives) of pro-plaintiff claim screening with this threshold. The difference between the two pro-plaintiff dotted lines represents the net benefit of pro-plaintiff claim screening. The optimal signal threshold here is set at 0.52 .

This graphical analysis, of course, does not prove that claim screening will always be optimal. The particular CDFs and probabilities are, after all, arbitrarily chosen. Indeed, even with these curves, a conclusion that claim screening produces net benefits reflects two premises: first, that the number of truly liable and truly not liable cases are equal, and second, that the costs of false positives and false negatives are equal. We will return to these assumptions in our formal analysis. The graph, nonetheless, usefully illustrates two intuitions: First, when even a noisy signal is sufficiently near the extremes of the 
probability distribution, the chance that the signal is misleading is relatively low, and the danger that claim screening will lead to bad results is relatively low as well. The second is that the optimal claim screening thresholds need not be symmetric and will depend on the shape of the CDFs.

\section{B. A Model Without Trial Costs}

As above, consider a set of cases in which the correct finding is either "liability" (denoted $\bar{L}$ ) or "no liability" (denoted $\overline{N L}$ ). For either type of case, the court system may find liability with one of two probability values: $p_{L \mid l o w}$ and $p_{L \mid h i}$, where $p_{L \mid l o w}<p_{L \mid h i}$. The probability $p \in\left[p_{L \mid l o w}, p_{L \mid h i}\right]$ may be thought of as the proportion of judges who would impose liability. (In the simulations of Part III, we allow for a distribution of probabilities.) Let $p_{N L \mid l o w}=1-p_{L \mid l o w}$ and $p_{N L \mid h i}=1-p_{L \mid h i}$. Let $\lambda_{\text {low } \mid \bar{L}} \in[0,1]$ represent the proportion of truly liable cases that have a probability of a liability finding at court of $p_{L \mid \text { low }}$. The remaining share $\lambda_{h i \mid \bar{L}}=\left(1-\lambda_{\text {low } \mid \bar{L}}\right)$ of truly liable cases has a probability of a liability finding $p_{L \mid h i}$ in each case. Let $\lambda_{\text {low } \mid \overline{N L}} \in[0,1]$ be the share of truly not liable cases that have a $p_{L \mid l o w}$ probability of a liability finding at court. This means a share $\lambda_{h i \mid \overline{N L}}=\left(1-\lambda_{\text {low } \mid \overline{N L}}\right)$ will have a probability $p_{L \mid h i}$ of a liability finding. This notation is summarized in Table 1.

Table 1: Proportion of Cases with Each Probability of Liability Finding Within Truly Liable and Truly Not Liable Cases

\begin{tabular}{|c|c|c|c|}
\hline & & \multicolumn{2}{|c|}{ Court's probability of finding liability } \\
\hline & & $p_{L \mid \text { low }}$ & $p_{L \mid h i}$ \\
\hline \multirow{2}{*}{$\begin{array}{l}\text { Correct } \\
\text { outcome type }\end{array}$} & Truly liable & $\lambda_{\text {low } \mid \bar{L}}$ & $\lambda_{h i \mid L}=\left(1-\lambda_{l o w \mid L}\right)$ \\
\hline & Truly not liable & $\lambda_{\text {low } \mid \overline{N L}}$ & $\lambda_{h i \mid \overline{N L}}=\left(1-\lambda_{l o w \mid N L}\right)$ \\
\hline
\end{tabular}

The only assumption we make about the accuracy of the court is that truly not liable cases have the lower probability of liability at court than truly liable cases. Specifically, we assume $\lambda_{\text {low } \mid \overline{N L}} \geq \lambda_{\text {low }} \mid \bar{L}$. Note that these assumptions are fairly general. They accommodate both a perfect court (i.e., $\lambda_{\text {low } \mid \overline{N L}}=1, \lambda_{\text {low } \mid \bar{L}}=0, p_{L \mid l o w}=0, p_{L \mid h i}=1$ ), as 
well as a completely uninformed court in which the probability of a liability finding bears no relation to the correct finding (i.e., $\lambda_{l o w} \mid \overline{N L}$ $\left.=\lambda_{\text {low } \mid \bar{L}}, p_{L \mid \text { low }}=p_{L \mid h i}\right)$.

As a baseline we first define the total expected social costs of court errors in the status quo. Let a represent the share of cases that are truly liable. Let the cost for a false no-liability finding equal $c_{N L \mid \bar{L}}$. Because $p_{N L \mid l o w}$ and $p_{N L \mid h i}$ are the proportions of judges who would find no liability for the groups of cases with a low and high probability of finding liability, respectively, the expected error cost from false noliability findings is $\alpha c_{N L \mid \bar{L}}\left(\lambda_{\text {low } \mid \bar{L}} p_{N L \mid l o w}+\lambda_{h i \mid \bar{L}} p_{N L \mid h i}\right)$. Assume a cost of $c_{L \mid \overline{N L}}$ per case that imposes false liability. The expected error cost from false-liability findings in the status quo is $(1-\alpha) c_{L} \mid \overline{N L}\left(\lambda_{\text {low }} \mid \overline{N L}\right.$ $\left.p_{L \mid l o w}+\lambda_{h i \mid \overline{N L}} p_{L \mid h i}\right)$. The expected costs of errors in the status quo can be expressed as:

(1) $E C_{S Q}=A\left(\lambda_{\text {low } \bar{L}} p_{N L l o w}+\lambda_{h i \bar{L}} p_{N L h i}\right)+\left(\lambda_{\text {low } \overline{N L}} p_{L l l o w}+\lambda_{h i \overline{N L}} p_{L \mid h i}\right)$

where $A$ is a constant term equal to $\alpha c_{N L \bar{L}} /(1-\alpha) c_{L \mid \overline{N L}}$, representing the relative expected cost of false no-liability findings to false liability findings.

The first term in (1) is the expected cost of the false no-liability findings and the second term is the expected cost of false liability findings. For now, we focus on the benchmark case in which $A=1$ (i.e., where the relative expected costs of false no-liability and false liability findings are equal). In particular, this covers the situation in which there are an equal number of truly liable and truly not liable cases, and the cost of each type of erroneous finding is equal. Later we discuss the importance of the value of $A$ and the implications of relaxing this assumption.

Suppose we observe neither the correct liability decision nor whether the value of $p$ is $p_{L \mid l o w}$ or $p_{L \mid h i}$ (the court's likelihood of finding liability, correctly or not) but instead observe a noisy signal $s \in[0,1]$ that contains information about $p$. For instance, this signal may be the interest rate charged in a third-party financing arrangement. A higher interest rate indicates a lower probability of a liability finding and damage recovery. We imagine a claim-screening policy parameterized by a pair of thresholds $t_{1} \leq t_{2}$. Under this policy, cases with $s$ observed below $t_{1}$ are automatically dismissed, those with $s$ above $t_{2}$ are automatically found liable, and those with $s$ between $t_{1}$ and $t_{2}$ proceed to trial as in the status quo.

In Lemma 1, we present necessary and sufficient conditions on the conditional distributions of a noisy signal $s$ such that a claimscreening policy will reduce error costs. To preview the results, a signal reduces court error if and only if the signal has greater odds 
than the court of reaching the correct finding among the subset of cases that are screened out. The conditions are equivalent to a specification in our graphical illustrations above in that the height of the benefits curve exceeds the costs curve, for some thresholds. Part (i) of the claim applies to the lower tail of the signal distribution (cases that are automatically dismissed) and (ii) applies to the upper tail (cases that are found automatically liable). Part (iii) says that if each tail taken alone has a cost-reducing claim-screening policy, then a policy that screens out cases on both tails using each threshold does even better. Here we present an intuitive statement of the lemma. The formal statement and proof are presented in the Appendix.

Lemma 1: If (1) the relative costs of false liability and false noliability findings are equal, and (2) courts satisfy a minimal condition of aggregate accuracy, namely, that courts are more likely than not to find no liability in truly not liable cases and liability in truly liable cases, the following hold:

(i) a beneficial pro-defendant claim-screening threshold exists if claim screening overturns more status quo liability findings among low-probability cases (i.e., cases more likely to have a correct outcome of not liable) than among high-probability cases (i.e., cases more likely to have a correct outcome of liable).

(ii) a beneficial pro-plaintiff claim-screening threshold exists if claim screening overturns more status quo no-liability findings among high-probability cases than among low probability cases.

(iii) both pro-defendant and pro-plaintiff claim-screening thresholds are beneficial if both (i) and (ii) hold.

The critical conditions (i) and (ii) are cost-benefit criteria. Consider expression (4) in the Appendix. On the benefit side of the ledger for pro-defendant claim screening are cases with low

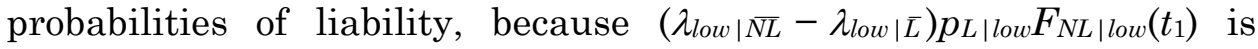
positive. This follows from the fact that truly not liable cases outweigh truly liable cases among those with $p_{L \mid l o w}$ (i.e., $\lambda_{\text {low } \mid \overline{N L}}>\lambda_{\text {low } \mid \bar{L}) \text {. This }}$ benefit must be balanced against the expected cost from applying prodefendant claim screening to cases with a high probability of liability, which sometimes also generate low signals and trigger automatic dismissal. For this group there is a net cost because truly liable cases outnumber truly not liable cases. Condition (i) says claim screening overturns more status quo liability findings among low-probability cases $\left(p_{L \mid \text { low }} F_{N L \mid \text { low }}\left(t_{1}\right)\right)$ than among high-probability cases $\left(p_{L \mid h i} F_{N L \mid h i}\left(t_{1}\right)\right)$. If this is so, then the benefits of pro-defendant claim screening exceed the costs.

The key question is when these conditions are met so that some form of claim screening is appropriate. How likely are conditions (i) and (ii) to be satisfied by some signal available to the court? We next 
present a corollary to the preceding claim illustrating a general set of signals satisfying these conditions. All that is required is that the signals be sufficiently informative near the extremes of the distribution.

The particular signal we consider is a weighted average of the (unobserved) probability of a liability finding by the court (either $p_{L \mid l o w}$ or $p_{L \mid h i}$ in any given case) and a random variable $r$ uniformly distributed on [0,1]. As the weight on $r$ approaches 1 , the signal approaches pure noise. We show that for any signal strength, there are always thresholds at which claims should be screened. For any positive value of the weight $w$ on the true probability, no matter how small, there will be some range of signal values at the extremes (i.e., near 0 and 1) which reveal the true underlying probability of liability for the case at hand. Because we assume $\lambda_{\text {low } \mid \overline{N L}}>\lambda_{\text {low } \mid \bar{L}}$, a minimum requirement of aggregate judicial accuracy, screening out claims based on such a signal will reduce the cost of errors. Here we provide an intuitive statement of this claim and present the formal statement and proof in the Appendix.

Claim 1: Consider any signal that is a weighted average of the court's probability of finding liability and a pure statistical noise term. Assume false liability findings and false no-liability findings are equally costly. Then claim screening based on such a signal yields net benefits.

Figure 3 graphically illustrates such a signal, for a value of $w$ such that some cases with intermediate signal values (between $v_{1}$ and $v_{2}$ ) proceed to trial. If we think of the signal value as the interest rate on a third-party financing arrangement, a high interest rate would be associated with a lower probability of a liability finding, hence a low signal value. Under a claim-screening regime, interest rates above a certain threshold would be automatically dismissed. 
Figure 3: Example of a Signal $v$ Where Extreme Cases Are Screened Out

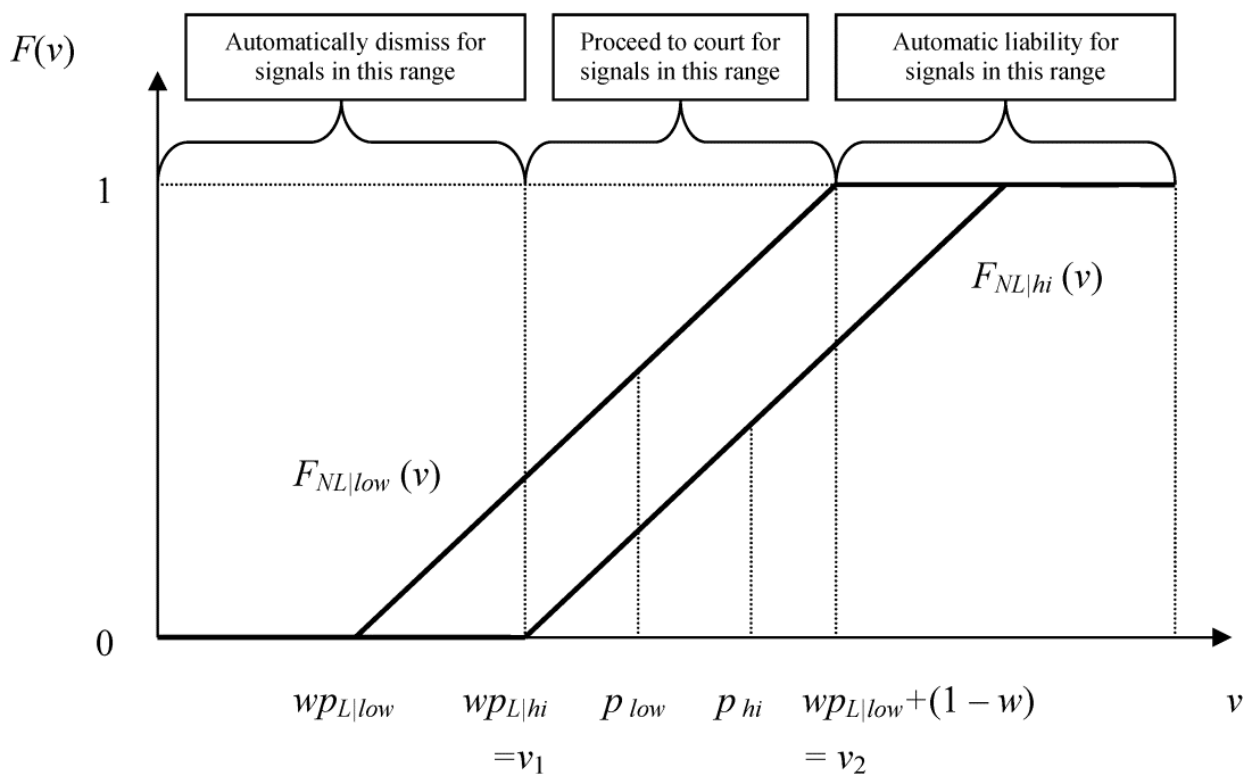

Recall that $A$ represents the relative importance of false noliability findings to false liability findings. The greater the value of $A$, all else equal, the less likely we are to see net benefits from the automatic dismissal of cases below a given threshold. At the same time, greater values for $A$ should increase the net benefit from finding automatic liability above a given threshold. If the expected cost of false liability increases relative to false no liability, we would need more accurate signals as the basis upon which to dismiss claims automatically. Likewise, we would tolerate less accurate signals upon which to base automatic liability findings. We have already seen that for $A=1$, both pro-defendant and pro-plaintiff claim screening can reduce costs relative to the status quo. In Claim 2 , we use the specific signal considered earlier to show that for any arbitrary value of $A$, at least one of the two types of claim screening will always reduce error costs relative to the status quo. Here we state Claim 2 intuitively and present the formal statement and proof in the Appendix.

Claim 2: Consider any signal that is a weighted average of the court's probability of finding liability and a pure statistical noise term. Then for any relative weighting of the costs of false liability findings and false no-liability findings, either pro-defendant or pro-plaintiff claim screening (or both) reduces error costs relative to the status quo. 


\section{A Model with Trial Costs}

The analysis thus far has assumed zero court costs. In general, the existence of court costs requires two modifications to our model. First, court costs under the status quo can lead some cases at the extremes-cases whose expected net benefits from going to trial are negative-to be dropped. Second, error costs should be adjusted to reflect the net difference between what defendants and plaintiffs actually pay and receive, respectively, and what they should optimally pay and receive. For instance, some of the error associated with finding a defendant falsely not liable may be offset if the defendant still has to pay substantial court costs.

The result of the first effect, other things being equal, is to reduce the potential savings from any given claim-screening policy. This is because as court costs increase, more cases at the extremes would be dropped anyway under the status quo. Indeed, in the extreme case where costs are so high that no cases go to court in the status quo, all cases would be dropped or settled in favor of the likely winner, and claim screening would offer no additional benefit. In a sense, increasing litigation costs when an objective signal of the likelihood of liability is available is an indirect way of screening claims. Deriving conditions under which a beneficial claim-screening policy exists requires taking this effect into account. Rather than repeating the exercise of Lemma 1 for the case of nonzero court costs, in this Section we assume such a policy exists and study how its thresholds might change in response to changes in court costs. We will show that the optimal thresholds increase in response to higher court costs, and that the first effect of higher court costs (more cases dropped in the status quo) is irrelevant to this response. The more cases that are dropped in the status quo due to higher court costs, the less claim screening reduces errors relative to the status quo. Of course, more cases dropped in the status quo may mean that the amount by which claim screening reduces errors (relative to the status quo) may decrease when court costs are higher.

Assume for simplicity that each party incurs fixed court costs $K$ in the event of a trial. The total cost associated with erroneous liability and no-liability findings are $c_{L \mid \overline{N L}}$ and $c_{N L \mid \bar{L}}$ (as before). However, we must now interpret these costs more specifically. In a truly not liable case, we assume the optimal outcome is for the defendant to pay nothing and the plaintiff to receive nothing. Similarly, in a truly liable case, the defendant should pay $D$ and the plaintiff should receive $D$. To measure the error cost associated with any given pair of payments, we add the plaintiff's and the defendant's 
absolute deviations from their optimal payments. ${ }^{17}$ For instance, in a truly not liable case that goes to court and is incorrectly found liable, the defendant pays $D+K$ and the plaintiff receives $D-K$. The optimal payments to/from each party in this case are zero, so (because we have assumed $D>K$ ) the total deviation from the optimum is $2 D$. As another example, court costs can introduce errors even in cases that are decided correctly. If a truly not liable case is correctly found not liable at court, both the defendant and plaintiff still pay $K$, resulting in a total deviation of $2 K$ from the optimal payments. To preserve comparison with the case of zero court costs, we define $c_{L \mid \overline{N L}}$ and $c_{N L} \mid \bar{L}$ as the costs of deviations of magnitude $2 D$ in truly not liable and truly liable cases, respectively. Accordingly, errors for other outcomes can be expressed (in proportion with their magnitudes) in terms of $c_{L \mid \overline{N L}}$ and $c_{N L} \mid \bar{L}$.

Table 2 summarizes the total errors associated with different findings in each type of case. Note that the errors for cases with incorrect findings are independent of court costs, because court costs reduce the error for one party by exactly the same amount they increase it for the other party. Court costs matter only for cases with correct findings. In these cases, court costs increase overall error costs by distorting the payments of both parties away from their optimal levels.

Table 2: Error Costs of Outcomes in the Presence of Court Costs $K$ Per Party

\begin{tabular}{|l|l|l|l|}
\hline \multicolumn{2}{|c|}{} & \multicolumn{2}{l|}{ Finding type } \\
\cline { 3 - 4 } & Liability finding & No-liability finding \\
\hline \multirow{2}{|c|}{$\begin{array}{l}\text { Correct } \\
\text { outcome } \\
\text { type }\end{array}$} & Truly liable & $c_{N L \mid \bar{L} K / D}$ & $c_{N L \mid \bar{L}}$ \\
\cline { 2 - 4 } & Truly not liable & $c_{L \mid \overline{N L}}$ & $c_{L \mid \overline{N L}} K / D$ \\
\hline
\end{tabular}

17. The optimal amounts a defendant should pay and a plaintiff should receive would generally flow from a larger model focusing on some specific litigation context, such as minimizing the overall costs of accidents, and need not be equal in magnitude. To simplify the discussion, we have assumed equal penalties for deviations from what the defendant should pay and deviations from what the plaintiff should receive. 
As before, given each (unobserved) potential probability of liability $p \in\left\{p_{L \mid l o w}, p_{L} \mid h i\right\}$, we have a signal $s$ of the underlying probability of liability, with cumulative distribution $F_{N L \mid p}(s)$. We assume that the plaintiff, defendant, and court share the same signal. (We leave the case of asymmetric information to the simulation model in the next part.) A plaintiff will drop any suit for which the expected gain from going to trial (the expected probability of winning, based on signal $s$, times the damage amount) is less than the court costs. More formally, a plaintiff will drop any suit for which the signal $s$ is such that $E(p \mid s)<K / D$. The signal is useful to the parties, even in the status quo, because they are able to update the probability that the court will find liability to the appropriate value between $p_{L \mid \text { low }}$ and $p_{L \mid h i}$. A defendant will pay full damages for any signal $s$ such that $E(p \mid s)>(1-K / D) .{ }^{18}$ When the parties observe a signal value $s$ (for instance, an interest rate on a third-party financing arrangement), they can calculate the implied probability of a court finding liability. To simplify notation, we therefore normalize realizations of the signal $s$ to equal the expectation of $p$ that they imply. Therefore $p_{L \mid \text { low }}<s<$ $p_{L \mid h i}$.

We will analyze nontrivial claim-screening policies given by $\left(t_{1} *, t_{2}{ }^{*}\right)$ satisfying $K / D<t_{1} *<t_{2} *<(1-K / D)$. These policies are nontrivial because they screen out some cases that would not have been dropped anyway in the status quo. To simplify later notation, let $Z_{l o w}$ and $Z_{h i}$ represent error costs in correctly adjudicated cases when the probability of liability is $p_{L \mid \text { low }}$ and $p_{L \mid h i}$, respectively. Recall that $A$

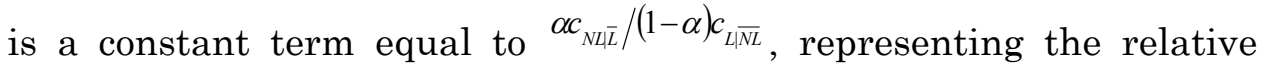
expected cost of false no-liability findings to false liability findings. To simplify notation, we express $Z_{l o w}$ and $Z_{h i}$ as a function of $A$, rather than the underlying cost terms described in Table 2.

(7a) $Z_{\text {low }}=\frac{K}{D}\left(A \lambda_{\text {low } \bar{L}} p_{\text {Llow }}+\lambda_{\text {low } \overline{N L}} p_{N L l o w}\right)$

(7b) $Z_{h i}=\frac{K}{D}\left(A \lambda_{h i \mid \bar{L}} p_{L \mid h i}+\lambda_{h i \mid \overline{N L}} p_{N L \mid h i}\right)$

Let $E C_{C S}\left(t_{1}^{*}, t_{2}^{*}, K\right)$ be the expected error costs of a claimscreening policy with thresholds $\left(t_{1}{ }^{*}, t_{2}{ }^{*}\right)$, when court costs at trial are $K$ per party.

18. Note that we assume that litigation in the status quo will involve only positiveexpected-value suits. The results, however, would be strengthened if we allowed for negativeexpected-value suits in the status quo because some of these suits would result in automatic findings of no liability. 
(8) $E C_{C S}\left(t_{1}^{*}, t_{2}^{*}, K\right)=E C_{C S}\left(t_{1}^{*}, t_{2}^{*}, 0\right)+Z_{\text {low }}\left(F_{\text {NLlow }}\left(t_{2}^{*}\right)-F_{\text {NLlow }}\left(t_{1}^{*}\right)\right)+Z_{h i}\left(F_{\text {NLhi }}\left(t_{2}^{*}\right)-F_{\text {NLhi }}\left(t_{1}^{*}\right)\right)$

The presence of court costs adds errors only for the subset of cases going to trial (the terms with $Z$ ). Even when the court reaches the correct decision in the status quo, court costs distort the payments of each party away from their optimal values. By eliminating this small distortion of optimal payments in correctly decided cases, claim screening generates an additional benefit relative to the situation in which court costs are zero. The next claim shows that the optimal claim-screening thresholds, if they exist between $K / D$ and $(1-K / D)$, move closer together when court costs increase. Once again, we provide an intuitive statement here and reserve the formal statement and proof for the Appendix.

Claim 3: Assume we have an optimal claim-screening policy characterized by thresholds $t_{1}{ }^{*}$ and $t_{2} *$. Then any increase in court costs implies that the optimal thresholds should move closer together (i.e., more cases should be automatically decided rather than going to court).

Higher court costs increase the expected error costs of cases going to trial without affecting the error costs of those that are screened out. On the margin, it therefore becomes worthwhile to screen out more cases.

To summarize our results in this Section, we have shown that a third-party signal, even if statistically noisy, can reduce the overall costs of false liability and no-liability findings, so long as (1) judges in the aggregate are more likely than not to reach the correct decision and (2) the signal is a minimally informative statistical predictor of aggregate judicial opinion. A claim-screening mechanism based on such a signal would automatically dismiss cases with signals indicating a very low probability of liability, find automatic liability in cases with signals indicating a very high probability of liability, and allow to proceed to trial those cases with intermediate signals. We have also shown how such claim-screening policies could be adjusted to account for variations in court costs, as well as variations in the relative weighting of the costs of false liability and false no-liability findings.

We have abstracted away somewhat from the settlementbargaining process, though incorporating it more explicitly would not affect the main results. To see how claim screening would adjust to the settlement-bargaining process, consider the following example for a court with a $5 \%$ error rate. In the status quo, if we assume that all cases settle for their expected value at court, all the truly liable cases will settle for $95 \%$ of full damages and all the truly not liable cases 
will settle for $5 \%$ of full damages. If we measure error as the deviation between what is actually paid and what should be paid (i.e., full damages in truly liable cases and no damages in truly not liable cases), this means a 5\% error in every case, the same overall error rate that we obtain in the no-settlement model. Introducing settlement aggregates idiosyncratic court error and spreads it evenly across all cases but does not reduce it. We still need a claim-screening mechanism to eliminate the idiosyncratic errors. Nonetheless, it may be useful to incorporate settlement and other features directly into the model, both to assess what claim-screening thresholds might be plausible and to explore tentatively the robustness of our conclusions. We now turn to that task.

\section{SIMULATION MODEL}

Our mathematical model is quite general, showing that there are some signals that should trigger claim screening without specifying what those signals should be. To obtain a better sense of the numbers, we need a more complicated model that incorporates settlement. Such a model is not likely to be mathematically tractable, however, so we turn to simulation. The heart of the simulation is a simple, general litigation model involving a plaintiff and a defendant. To calculate each data point on the graphs in the following analysis, the computer played this litigation game 50,000 times. In its most basic form (we will consider some variations later), the game works as follows: The plaintiff sues the defendant for damages $D$, which are assumed to be agreed upon in advance (for simplicity). The actual probability that the plaintiff will eventually win the lawsuit, $p$, is drawn from a uniform distribution from 0 to 1 . The plaintiff, defendant, and a third party each independently estimate this probability without bias but with noise, producing estimates $p_{\mathrm{P}}, p_{\mathrm{D}}$, and $p_{\mathrm{T}}$. The degree of noise depends on the value of noise coefficients $n_{\mathrm{P}}, n_{\mathrm{D}}$, and $n_{\mathrm{T}}$, respectively. ${ }^{19}$

The plaintiff and defendant each calculate the expected value of trial based on their respective estimates, $E V_{\mathrm{P}}$ and $E V_{\mathrm{D}}$, taking into account both the cost of litigation $\left(K_{\mathrm{P}}\right.$ and $\left.K_{\mathrm{D}}\right)$ and the claim-screening legal regime. (In the ordinary case, $E V_{\mathrm{P}}>0$ and $E V_{\mathrm{D}}<0$.) The case

19. Each estimate $p_{i}=f\left(p+N\left(n_{i}\right)\right)$, where $N$ outputs a random number drawn from a normal distribution with mean 0 and standard deviation $n_{i}$, and $f(x)$ is a function that calculates the expected value of $p$ for any estimate $x$ biased by adding a random normal deviate, given the initial distribution of cases and the particular value of $n_{i}$. We calculated $f(x)$ using Monte Carlo techniques. While it is not necessarily the case that $0<p+N\left(n_{i}\right)<1$, it will always be the case that $0<p_{i}<1$. Note that as $n_{i}$ increases, $p_{i}$ will approach 0.50 . 
will have a settlement range if $E V_{\mathrm{P}}+E V_{\mathrm{D}}<0$. When this is so, the case will settle at the midpoint of the settlement range. When it is not, then either party may still choose to default; $P$ will default (i.e., drop the case) if $E V_{\mathrm{P}}<0$, and $D$ will default (i.e., accept an adverse judgment) if $-E V_{\mathrm{D}}>D$. If neither party defaults, the case goes to trial. A random number $r$ is generated from a uniform distribution from 0 to 1 , and the plaintiff wins the lawsuit if $p>r$. If the plaintiff wins, the defendant pays the plaintiff $D$.

A disadvantage of simulation models is that particular values have to be chosen for the relevant parameters, and simulation models can provide no assurance about generalizability of the results for combinations of parameter values not selected. Nonetheless, simulation models make it relatively easy to examine the consequences of changing both the parameter values and the structure of the simulation itself. We thus assigned baseline values for the parameters, admittedly with some arbitrariness, and later we will consider the effects of changing some of these baseline values. In all subsequent simulations, these baseline values are used unless otherwise indicated. In particular, we assumed that $D=100$ and that $K_{\mathrm{P}}=K_{\mathrm{D}}=15 .{ }^{20}$ In addition, the baseline simulation set $n_{\mathrm{P}}=n_{\mathrm{D}}=0.15$, and $n_{\mathrm{T}}=0.25$. These noise coefficients correspond to an average absolute error in estimating $p$ of about 0.1 for both the plaintiff and defendant, and 0.15 for the third party. Whether our estimate of $n_{\mathrm{T}}$ is plausible depends on the technology used to induce third-party estimates, but we believe that this estimate is quite conservative. Note that if $p=0.50$, then an estimate randomly drawn from a uniform distribution between 0.20 and 0.80 would also produce an average absolute error of 0.15 .

To measure the effectiveness of the legal system with and without claim screening, we calculated average overdeterrence errors and average underdeterrence errors. When a defendant pays money even though the correct answer would require the defendant to pay nothing, the defendant is overdeterred and presumably takes excessive precautions. In such a case, the net amount of money spent by the defendant counts as the overdeterrence error. When a

20. We recognize that some empirical studies support a value closer to 25. See Donohue, supra note 13 , at $201 \mathrm{n} .25$. We chose a value of 15 largely because with a value of 25 , the rate of settlement is approximately 0.99 or higher for many of the cases considered, making comparisons less interesting. Using a value of 25 would produce an unrealistically high settlement rate on this model because of the assumption that the decision to go to trial is made once and forever at the outset of litigation. If Donohue's 25 includes costs that are sunk before a commitment to going to trial, we could reconcile the two figures by interpreting 15 as only those costs incurred after the decision to go to trial is made. 
defendant pays less than full damages in a case in which the correct answer is to pay full damages, the defendant is underdeterred. In such a case, the amount by which the defendant's payments fall short of full damages counts as the underdeterrence error. Our measures of the defendant's payments include trial costs. So, for example, if a trial in which the defendant should be found liable results in the defendant paying $\$ 100$ in damages, but also $\$ 15$ for the defendant's legal expenses, the case counts as producing $\$ 15$ in overdeterrence error and $\$ 0$ in underdeterrence error. In no single case will there be both overdeterrence and underdeterrence errors. Note that damages can be expressed in terms of over- or undercompensation errors, but using the deterrence framework is straightforward.

Calculating the errors requires an assumption about what answer is correct in a particular case. Our baseline assumption is that the probability that a position is correct is equal to the proportion of decisionmakers who would adopt that position. Thus, when the random number generator draws $p=0.25$ from a uniform distribution, there is a 0.25 probability that the plaintiff should win and a 0.75 probability that the defendant should win. The simulation thus performs an additional random number generation to choose between these possibilities. Thus, $75 \%$ of the time, the simulation will assume that the correct legal answer is for the defendant to win and pay nothing, and $25 \%$ of the time, the simulation will assume that the correct answer is for the plaintiff to win and receive $D$ from the defendant. We will, however, relax this assumption later, considering both the possibility that majorities are disproportionately correct (so that when $90 \%$ of judges would rule for $D$, there is greater than a 0.9 probability that this is the correct answer) and the possibility that majorities are not quite proportionately correct (so that when $90 \%$ of judges would rule for $D$, there is less than a 0.90 probability that this is the correct answer).

For most of the simulations reported here, the results for overdeterrence error and underdeterrence error were qualitatively similar, although overdeterrence error was systematically somewhat higher as a result of legal fees. We thus simply report the sum of these measures, ${ }^{21}$ denoted "error costs," recognizing that in some legal

21. The sum, not the difference, is the appropriate measure. Underdeterrence and overdeterrence costs do not cancel out because the costs occur in different cases. Consider a tort system that imposed no damages on a defendant in a case in which the defendant should have taken a precaution and then imposed damages on a defendant in a case in which the defendant should not have taken and did not take a precaution. This legal system will not produce appropriate incentives to take precautions, regardless of whether the defendant in the two cases 
contexts, the welfare consequences of a marginal dollar in overdeterrence may differ from the consequences of a marginal dollar in underdeterrence. This measure provides a proxy for the overall inaccuracy of the legal system. The measure is not, however, a general measure of the total welfare consequences of the legal system, which also depend on the trial costs. Although trial costs may affect deterrence error-for example, by increasing the extent of overdeterrence - they also have direct welfare consequences.

\section{A. Change in Signal Strength}

We begin by considering how claim screening affects error costs in the baseline case and when the third party receives two signals of variant strengths. The two alternative values for $n_{\mathrm{T}}$ are 0.15 (a relatively strong signal providing the third party a forecasting ability equal to that of each of the parties) and 0.35 (a very weak signal). For each of the signals, we consider different thresholds beyond which the plaintiff and the defendant would automatically win. We use symmetrical thresholds, such as 0.10 for pro-defendant claim screening and 0.90 for pro-plaintiff claim screening. A threshold of 0 for the plaintiff and 1 for the defendant is equivalent to a regime of no claim screening, and a threshold of 0.50 for each party is equivalent to a regime in which all claims are resolved on the basis of the thirdparty estimate. We assume in these simulations that the claim screening takes place before any settlement negotiations. ${ }^{22}$

Figure 4 illustrates the results. The $\mathrm{x}$-axis reports the threshold for determining whether the plaintiff automatically wins; in all simulations, the corresponding threshold for whether the defendant automatically wins was equal to (1 - "plaintiff threshold"). Unsurprisingly, error is lower with the stronger signal. More surprisingly, the analysis suggests that the optimal thresholds are relatively close to 0.50 - that is, a relatively large number of cases should be automatically screened to minimize the absolute error. Optimal thresholds fall between $(0.50,0.50)$ and $(0.40,0.60)$ for both

happens to be the same party. The party will have an incentive to take an inefficient precaution and not to take an efficient one.

22. Had we not adopted this assumption, the simulation would have required an initial round of settlement negotiations in which each party estimates the probability that the third party will announce a value above or below the threshold. We anticipate that social welfare results would be similar, though not quite as dramatic, in a regime in which settlement could occur before claim screening. Litigants would recognize that relatively frivolous claims would very likely be dismissed even before trial, thus dramatically reducing the danger of an idiosyncratic decisionmaker at trial, but defendants might still agree to very low settlements for lowprobability claims. 
the baseline case and the strong signal, and between $(0.40,0.60)$ and $(0.35,0.65)$ for the weak signal. Note that screening out cases at the ends of the probability continuum makes almost no difference, because many such cases settle anyway, and it is rare for the signal to be quite that strong.

Figure 4: Effect of Third-Party Signal Strength

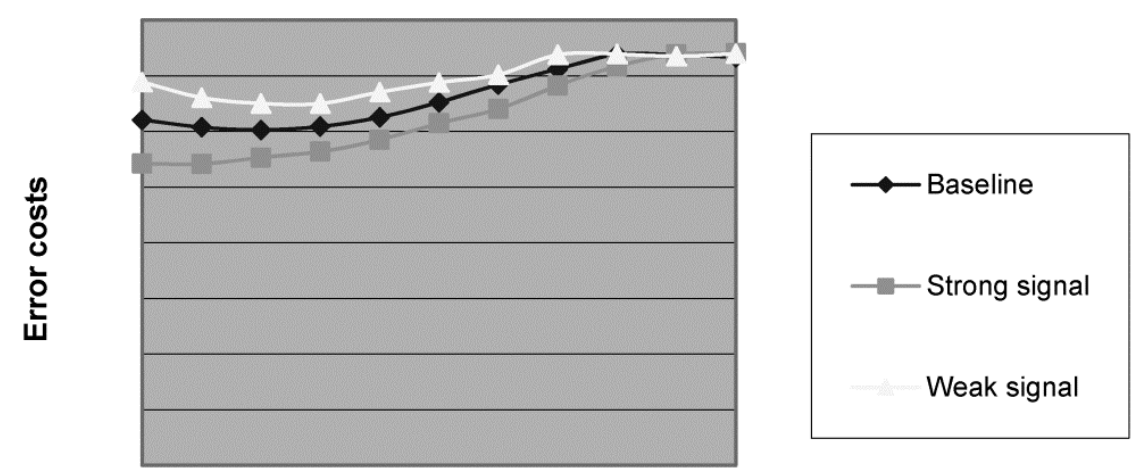

Plaintiff wins if signal $>x$ (defendant wins if signal $<1-x)$

The basic shape of the error-costs curves does not change when we alter the strength of the parties' signals. Figure 5 again illustrates the baseline case, along with cases for which the parties' signal strengths are strong $\left(n_{\mathrm{P}}=n_{\mathrm{D}}=0.05\right)$ or weak $\left(n_{\mathrm{P}}=n_{\mathrm{D}}=0.25\right)$, holding constant the third parties' signal strength. With the strong signal, error costs decline modestly from signal thresholds of $(0.50,0.50)$ to $(0.35,0.65)$ before rising markedly and then moving toward the ends of the probability continuum. This is because all cases with a strong signal settle, reducing a principal benefit of claim screening (eliminating the error costs associated with the costs of trial itself). We also tested the case in which only one party's signal is stronger or weaker, increasing the asymmetry of the parties' information. However, because the resulting curves are almost identical to Figure 5 , although a bit closer together toward the right end of the graph, we do not include the chart separately here. 
Figure 5: Effect of Party Signal Strength

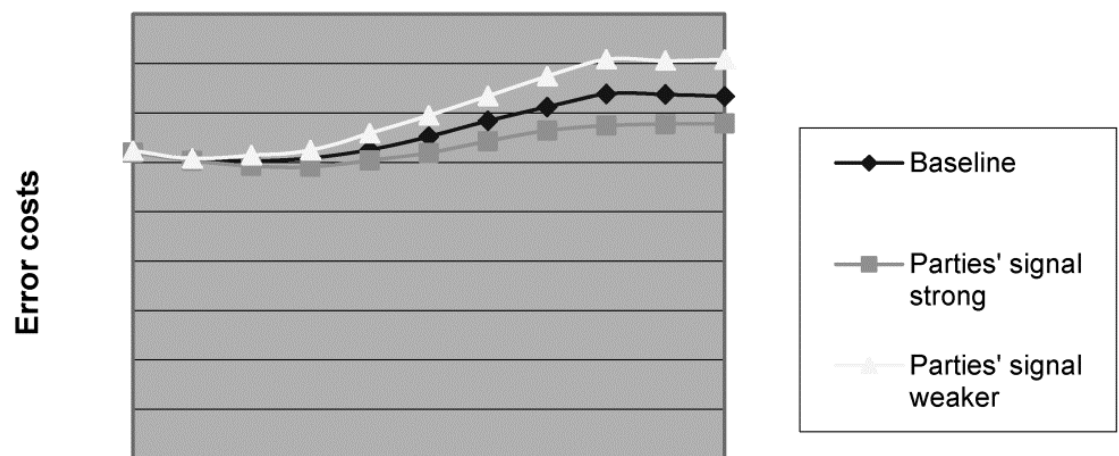

Plaintiff wins if signal $>x$ (defendant wins if signal $<1-x)$

\section{B. Trial Costs}

We also altered our assumptions about the level of trial costs. We tested a high trial-cost case $\left(K_{\mathrm{P}}=K_{\mathrm{D}}=25\right)$ and a low trial-cost case $\left(K_{\mathrm{P}}=K_{\mathrm{D}}=5\right)$. As Figure 6 illustrates, these variations had almost no effect on the shape of the error-costs curves (even though the changes had predictable effects on settlement rates in unscreened cases). Varying only one party's trial costs had almost no effect; the graph illustrating this is also omitted. 
Figure 6: Effect of Parties' Trial Costs

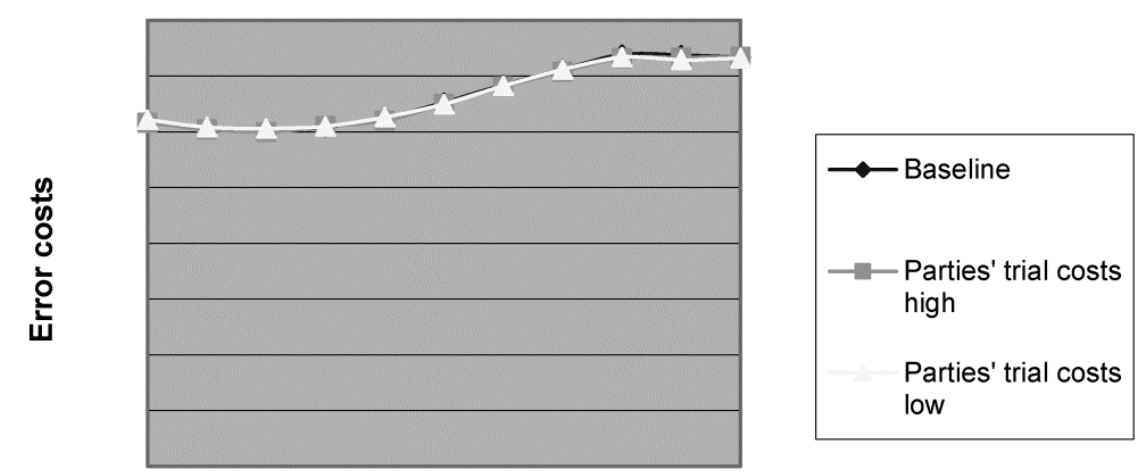

Plaintiff wins if signal $>x$ (defendant wins if signal $<1-x)$

\section{Majoritarian Correctness}

The analysis so far has assumed that the probability that the plaintiff should win equals $p$. Yet the probability that the plaintiff should win could be more or less than that. We thus considered two alternative conditions, the "majorities-strong" condition and the "majorities-weak" condition, as illustrated in Figure 7. When majorities are strong, the fact that a majority agrees on who should win provides greater reason to believe in that outcome than when majorities are weak. The probability that the plaintiff should win is set equal to $0.50[1-2(0.50-p)]^{\alpha}$ for $p \leq 0.50$ and equal to $1-0.50[1-2(p-0.5)]^{\alpha}$ for $p>0.50$. In the majorities-strong condition, $\alpha=2$, and in the majorities-weak condition, $\alpha=0.50$. For example, in the cases in which the plaintiff will win with 0.75 probability, the majorities-strong condition indicates the plaintiff should win with 0.88 probability and the majorities-weak condition indicates the plaintiff should win with .65 probability. Error costs are highest overall in the majorities-weak condition, because the court system in that condition is least likely to reach the correct result. Neither the majorities-weak nor the majorities-strong condition, however, has much effect on the optimum values of the signal thresholds or on the shape of the errorcosts curve. 


\section{Figure 7: Effect of Majoritarian Correctness}

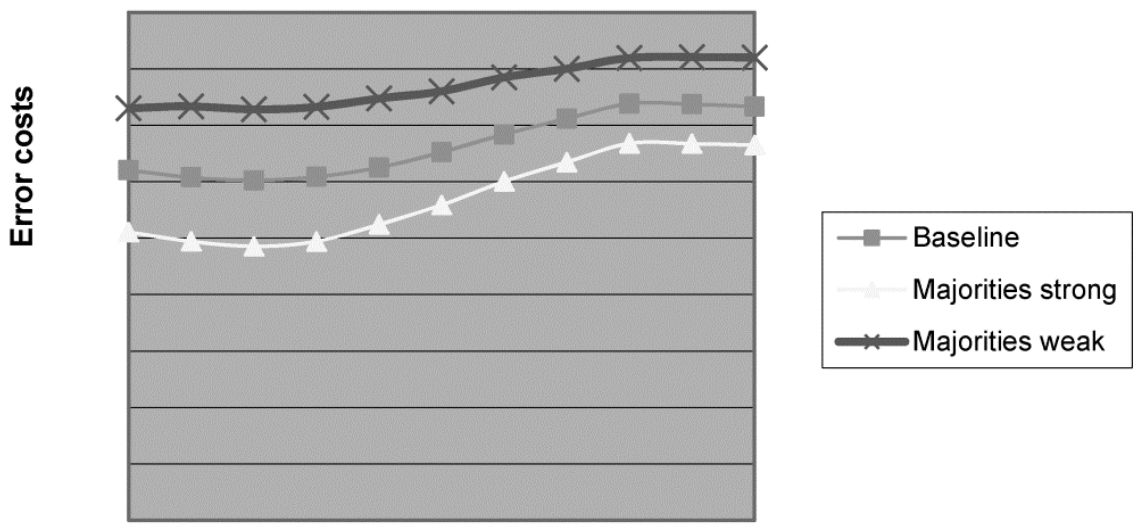

Plaintiff wins if signal $>x($ defendant wins if signal $<1-x)$

\section{Costliness of the Signal}

Our analyses so far have assumed that the third-party signal is costless. This may make sense if the signal is the result of gatekeeping by a litigation finance company that would have occurred anyway. But in other situations, procuring a signal will be costly; if one or both parties bear the cost, that cost must be taken into account in evaluating the effectiveness of the legal system. The transaction costs matter both in and of themselves and because they might affect deterrence error. If the plaintiff alone bears the cost of the signal, that will not affect the effectiveness of underdeterrence or overdeterrence. Because our analysis assumes that the universe of cases is determined exogenously, we do not consider the possibility that plaintiffs might not bring some relatively low-probability-of-success cases at all as a result of the cost of the signal. Thus, for analytical thoroughness, we adopt the reverse assumption, that the defendant must bear the cost of the signal.

Figure 8 assesses the effect of changing the cost of the thirdparty signal, assuming that the defendant bears the cost in each of the three regimes. The quality of the signal is constant; this figure assesses only the extent to which different possible costs of obtaining a signal of baseline quality might impact deterrence error. The low-cost signal costs the defendant 5, and the high-cost signal costs the defendant 15 (equal to each party's trial costs). The cost of the signal 
has only a slight effect when there is no claim screening (at the far right of the figure). Here, the vast majority of cases settle at some compromise value, and the extra cost imposed on the defendant is about as likely to make up for underdeterrence as it is to exacerbate overdeterrence. When claim screening is used, however, the high-cost signal substantially increases error costs near thresholds of $(0.50$, 0.50) and reduces the benefits of claim screening. If claim screening costs the defendant as much as a trial, then, from the perspective of optimizing deterrence, it makes sense to preserve the trial for close cases. With the low-cost signal, however, claim screening is still optimized at thresholds around $(0.40,0.60)$. The intuition is that claim screening is likely to reduce error costs only if the cost of the signal is less than the cost of trial, because much of the deterrence value of claim screening arises from the reduction of trial costs. Because the goal of claim screening is only to produce a noisy signal of the expected trial value, this should generally be achievable.

\section{Figure 8: Effect of Costly Signal}

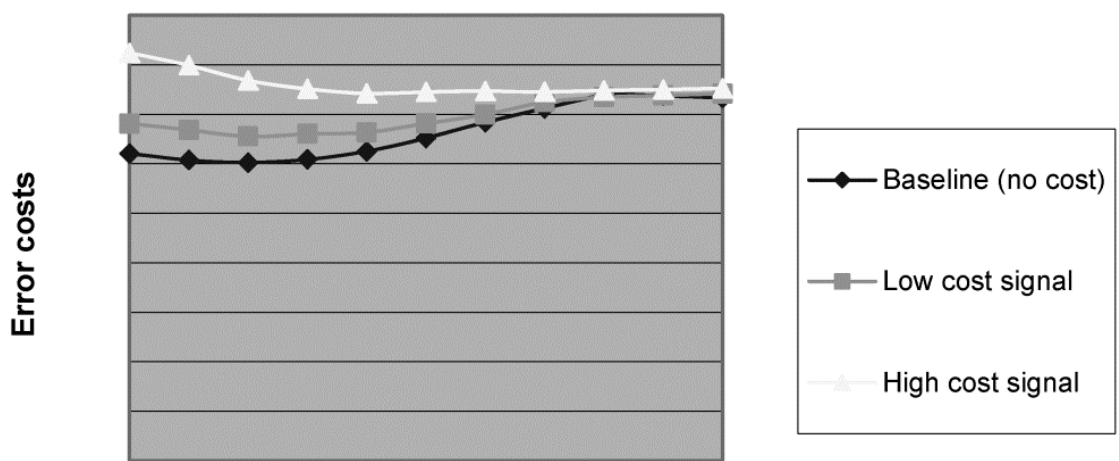

Plaintiff wins if signal $>x$ (defendant wins if signal $<1-x)$

\section{CONCLUSION}

The mathematical and simulation analyses presented here suggest that if a signal of case quality is available and sufficiently strong, it may often make sense to resolve a case conclusively on the basis of that signal. The mathematical model does not indicate how strong the signal must be to justify claim screening, but the 
simulation model seems to indicate that with an unbiased signal, claim screening may be optimally beneficial for cases with probabilities of victory roughly below 0.40 or above 0.60 . In the context of litigation finance, this suggests that the plaintiff should be allowed to seek third-party financing only if the financing company agrees to offer fee shifting at a level that would lead the financing company to screen out cases where it believes that the plaintiff has less than a 0.40 probability of winning.

It is beyond the scope of this Article to determine just what the optimal fee-shifting level is, but a basic regime in which the fees are shifted seems unlikely to screen claims in which the plaintiff has a higher probability of winning than that. Even with fee shifting, many cases will settle. Assuming that only $80 \%$ of cases settle, if the plaintiff prevails in $40 \%$ of the remaining $20 \%$ of cases (thus, $8 \%$ ), the expected cost of fee shifting would be only approximately $4 \%$ of legal fees $(12 \%-8 \%)$, and this assumes further that the other party agrees to the offer of fee shifting. As long as the average interest payment from the plaintiff exceeds this level in the remaining $80 \%$ of cases, the investment is still a beneficial one. It thus seems likely that a requirement forcing a litigation finance company to agree to fee shifting would produce a relatively small amount of claim screening, less than would be socially optimal. Thus, such a requirement would likely increase welfare relative to a regime in which litigation finance is offered without restriction. Over time, more dramatic screening mechanisms, such as double fee shifting, might be employed.

Our analysis also suggests that claim screening might be used in other cases, even if the mechanism is costly. Although we recognize that claim screening is a more radical change to the legal process than mere regulation of litigation finance, which would likely encounter due process and other objections, our analysis suggests that it could be beneficial. One possible approach would be to require all parties to obtain litigation finance in a way that ensures that the party's chance of prevailing exceeds some threshold. While it seems unlikely that such a requirement would be grafted onto the legal system, one can imagine more incremental change, first by regulating litigation finance and later by requiring litigation finance in cases in which there is reason to suspect that the plaintiff's case is weak.

Judges already make preliminary assessments under existing claim-screening mechanisms, such as the dismissal of a case for failure to state a claim ${ }^{23}$ and issuance of summary judgment. ${ }^{24}$ In

23. See, e.g., FED. R. CIV. P. 12(b)(6).

24. See, e.g., FED. R. CIV. P. 56. 
theory, these mechanisms are not explicitly probabilistic in nature. They generally ask whether the plaintiff would prevail if the facts are as claimed and whether there is a "genuine issue as to any material fact." The summary judgment standard has long been seen as only requiring parties to meet their burdens of production. ${ }^{25}$ Recent Supreme Court cases have given judges more flexibility to dismiss cases that they view as relatively unlikely to prevail. ${ }^{26}$ Thus, in practice, judges may sometimes dismiss or issue summary judgment in cases where the evidence on a dispositive issue is extremely onesided. To the extent this is so, our model may approximate existing practices. Moreover, our model suggests a potential compromise between those who believe that giving judges more flexibility to grant summary judgment is beneficial and those who believe that judges are poorly equipped to make probabilistic judgments of this sort. Judges could be given great flexibility to dismiss cases on summary judgment, but parties whose cases are dismissed would subsequently have the opportunity to obtain litigation financing under a contract if terms imply a reasonable chance of victory. Thus, litigation finance would be required only in cases in which a judge doubted a party's case. Our purpose has not been to identify precisely the situations in which litigation finance would be required, or in which preexisting litigation finance contracts would be used to determine whether claims should be screened. But our analysis has shown that claim screening based on a signal might be beneficial, and litigation finance agreements, voluntary or not, are a possible source of information on claim strength.

25. See Celotex Corp. v. Catrett, 477 U.S. 317, 327 (1986) (elaborating on the burdenshifting framework).

26. See Ashcroft v. Iqbal, 556 U.S. 662, 678 (2009) (detailing a court's authority to dismiss a complaint that offers only conclusions and finding that pleadings require more than a "thedefendant-unlawfully-harmed-me accusation"); Bell Atl. Corp. v. Twombly, 550 U.S. 544, 545 (2007) (holding that a complaint requires some factual matter, whereas a bare assertion of conspiracy is insufficient to meet the pleading standard). 


\section{APPENDIX}

In this appendix we present the formal statements and proofs of the claims in the mathematical section of the paper.

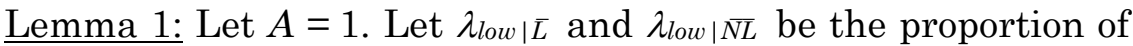
truly liable and not liable cases, respectively, that have a $p_{L \mid l o w}$ probability of a liability finding at court. The remaining cases in each group have a $p_{L \mid h i}$ probability of a liability finding at court. Assume $\lambda_{\text {low } \mid \overline{N L}}>\lambda_{\text {low } \mid \bar{L}}$. Let $s \in[0,1]$ be a signal of a court's (unobserved) probability of finding liability in a given case $p \in\left\{p_{L \mid l o w}, p_{L \mid h i}\right\}$. Assume this signal has cumulative conditional distribution functions $F\left(s \mid p_{i}\right), i \in\{L|l o w, L| h i\} . \quad$ To simplify notation, denote $F\left(s \mid p_{L \mid l o w}\right)=F_{N L \mid l o w}(s) \quad$ and $\quad F\left(s \mid p_{L \mid h i}\right)=F_{N L \mid h i}(s) . \quad$ Define $F_{L \mid \text { low }}(s)=1-F_{N L \mid \text { low }}(s)$ and $F_{L \mid h i}(s)=1-F_{N L \mid h i}(s)$. Denote the total error cost of a claim-screening policy with lower threshold $t_{1}$ and upper threshold $t_{2}$ as $E C_{c s}\left(t_{1}, t_{2}\right)$ with $0<t_{1}<t_{2}<1$. According to such a policy, cases with $s<t_{1}$ are automatically dismissed, those with $s>t_{2}$ are automatically liable, and those with $t_{1} \leq s \leq t_{2}$ are adjudicated as in the status quo. Consider the following conditions:

(2a) There exists $0<s_{1}$ such that

$$
\mathrm{p}_{\mathrm{L} \mid \text { low }} \mathrm{F}_{\mathrm{NL} \mid \text { low }}\left(\mathrm{s}_{1}\right)>\mathrm{p}_{\mathrm{L} \mid h i} \mathrm{~F}_{\mathrm{NL} \mid h i}\left(\mathrm{~s}_{1}\right)
$$

(2b) There exists $s_{2}<1$ such that

$$
\mathrm{p}_{\mathrm{NL} \mid \text { low }} \mathrm{F}_{\mathrm{L} \mid \text { low }}\left(\mathrm{s}_{2}\right)<\mathrm{p}_{\mathrm{NL} \mid h i} \mathrm{~F}_{\mathrm{L} \mid h i}\left(\mathrm{~s}_{2}\right)
$$

Then:

(i) a claim-screening policy $\left(t_{1}{ }^{*}, 1\right)$ exists such that $E C_{C S}\left(t_{1}{ }^{*}, 1\right)<E C_{S Q}$ if and only if (2a) holds

(ii) a claim-screening policy $\left(0, t_{2}{ }^{*}\right)$ exists such that $E C_{C S}\left(0, t_{2}{ }^{*}\right)<E C_{S Q}$ if and only if

(2b) holds

(iii) for any policies in (i) and (ii) such that $0<t_{1}{ }^{*}<t_{2}{ }^{*}<1$, the combined policy $\left(t_{1}{ }^{*}\right.$,

$\left.t_{2}{ }^{*}\right)$ satisfies $E C_{C S}\left(t_{1}{ }^{*}, t_{2}{ }^{*}\right)<E C_{C S}\left(0, t_{2}{ }^{*}\right)$ and $E C_{C S}\left(t_{1}{ }^{*}, t_{2}{ }^{*}\right)<E C_{C S}\left(t_{1}{ }^{*}, 1\right)$

Proof: Under a given claim-screening policy $\left(t_{1}, t_{2}\right)$, expected error costs from incorrect findings are:

$$
\begin{aligned}
& E C_{C S}=\left(F_{N L l \text { low }}\left(t_{1}\right) \lambda_{\text {low } \bar{L}}+F_{N L \mid h i}\left(t_{1}\right) \lambda_{h i \bar{L}}\right)+\left(F_{\text {Llow }}\left(t_{2}\right) \lambda_{\text {low } \overline{N L}}+F_{L \mid h i}\left(t_{2}\right) \lambda_{h i \mid \overline{N L}}\right) \\
& +\left(\lambda_{\text {low } \bar{L}} p_{\text {NLlow }}+\lambda_{\text {low } \overline{\mathbb{N} L}} p_{L l \text { low }}\right)\left(F_{N L l o w}\left(t_{2}\right)-F_{\text {NLlow }}\left(t_{1}\right)\right)+\left(\lambda_{h i \bar{L}} p_{N L \mid h i}+\lambda_{h i \mid \bar{N} L} p_{L \mid h i}\right)\left(F_{N L h i}\left(t_{2}\right)-F_{N L h i}\left(t_{1}\right)\right)
\end{aligned}
$$

The first term in (3) represents false, automatic no-liability findings, the second term represents false, automatic liability findings, the third term represents mistakes at trial for low-probability-of-liability cases, and the fourth term represents mistakes at trial for highprobability-of-liability cases. To show (i), note that the difference in error costs $E C_{S Q}-E C_{C S}\left(t_{1}, 1\right)$ can be expressed as:

$$
\left(\lambda_{\text {low } \overline{N L}}-\lambda_{\text {low } \bar{L}}\right)\left(F_{\text {NLlow }}\left(t_{1}\right) p_{\text {Llow }}-F_{N L \mid h i}\left(t_{1}\right) p_{L \mid h i}\right)
$$


Condition (2a) implies that this expression is positive for some $s_{1}=t_{1}$. To establish the existence of a claim-screening policy, let $t_{1}{ }^{*}=s_{1}$. Now suppose we have such a cost-reducing claim-screening policy. This means (4) is positive for $t_{1}=t_{1} *$. Then letting $s_{1}=t_{1}$ * establishes (2a). The proof for (ii) is similar and is omitted. Finally, to show (iii), note that $E C_{S Q}-E C_{C S}\left(t_{1}{ }^{*}, 1\right)=E C_{C S}\left(0, t_{2}{ }^{*}\right)-E C_{C S}\left(t_{1}{ }^{*}, t_{2}{ }^{*}\right)$ and $E C_{S Q}-E C_{C S}\left(0, t_{2}^{*}\right)=E C_{C S}\left(t_{1} *, 1\right)-E C_{C S}\left(t_{1}{ }^{*}, t_{2}{ }^{*}\right)$

Claim 1: Define the signal $v=w p+(1-w) r$, where $p \in\left\{p_{L} \mid\right.$ low, $\left.p_{L \mid h i}\right\}, w$ is an arbitrary weighting parameter satisfying $0<w<1$, and $r$ is a random variable uniformly distributed on $[0,1]$. Then any such signal satisfies conditions (2a) and (2b) of Lemma 1 , and there exist thresholds for which claim screening reduces costs relative to the status quo.

Proof: Because $r$ is uniformly distributed on [0,1], $v$, itself a function of $r$, is also a random variable uniformly distributed on [ $w p$, $w p+(1-w)]$. Letting $p$ equal each of its two possible values $\left(p_{L \mid l o w}\right.$ and $p_{L \mid h i}$ ) we can express the two conditional cumulative (uniform) distribution functions for $v$ as $F_{N L \mid l o w}(v)=\left(v-w p_{L \mid l o w}\right) /(1-w)$ for $v$ $\epsilon\left[w p_{L \mid l o w}, w p_{L \mid l o w}+(1-w)\right]$, and $F_{N L \mid h i}(v)=\left(v-w p_{L \mid h i}\right) /(1-w)$ where $v \in\left[w p_{L \mid h i}, w p_{L \mid h i}+(1-w)\right]$.

Assume without loss of generality that the two conditional CDFs overlap, so that $w p_{L \mid h i}<\left[w p_{L \mid l o w}+(1-w)\right]$. Define the claimscreening thresholds as $\left(v_{1}, v_{2}\right)=\left(w p_{L} \mid h i,\left[w p_{L} \mid l o w+(1-w)\right]\right)$. We have chosen the lower threshold so that any realization $v<v_{1}$ implies the true probability is $p_{L \mid l o w}$. Automatically dismissing all such cases would reduce the error cost by $p_{L \mid \text { low }}$ for each truly not liable case but increase the error cost by $p_{L \mid l o w}$ for each truly liable case, relative to the status quo. However, the not liable cases outnumber the liable cases among cases with $p=p_{L \mid l o w}$ (recall that we assumed $A=1$ and

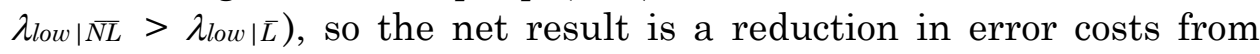
claim screening on very low signals. Likewise, when we observe signals greater than $v_{2}$, we know they could have arisen only if the case had a probability of liability $p=p_{L \mid h i}$. By parallel reasoning, finding automatic liability among these cases reduces error costs relative to the status quo. Thus, because claim screening improves outcomes relative to the status quo for ranges of the signal near 0 and 1 and does not change the outcomes for all other intermediate values of the signals (where cases proceed to trial), error costs are lower under this claim-screening policy than under the status quo.

Claim 2: As before, define the signal $v=w p+(1-w) r$, where $p$ $\epsilon\left\{p_{L \mid l o w}, p_{L \mid h i}\right\}, w$ is an arbitrary weighting parameter satisfying $0<w$ $<1$, and $r$ is a random variable uniformly distributed on $[0,1]$. Then, for any value of $A,(2 \mathrm{a})$ or (2b) (or both) are satisfied. Consequently, 
either pro-defendant or pro-plaintiff claim screening (or both) reduces error costs relative to the status quo.

Proof: As in Claim 1, define the claim-screening thresholds as $\left(v_{1}, v_{2}\right)=\left(w p_{L} \mid h i, \quad\left[w p_{L \mid l o w}+(1-w)\right]\right)$. Incorporating $A$ into the expression, we now write the difference in error costs from prodefendant claim screening $E C_{S Q}-E_{C S}\left(v_{1}, 1\right)$ as:

(5) $\left(\lambda_{\text {low } \overline{N L}}-A \lambda_{\text {low } \bar{L}}\right) F_{N L l o w}\left(v_{1}\right) p_{L \mid l o w}+\left(\lambda_{h i \overline{\mid N L}}-A \lambda_{h i \bar{L}}\right) F_{N L \mid h i}\left(v_{1}\right) p_{L \mid h i}$

Note that when $A=1$, this condition reduces to (4), because $F_{N L \mid h i}\left(v_{1}\right)=0$. The difference in error costs from pro-plaintiff claim screening $E C_{S Q}-E C_{C S}\left(0, v_{2}\right)$ is:

$\left(A \lambda_{\text {low } \bar{L}}-\lambda_{\text {low } \overline{N L}}\right) F_{L l o w}\left(v_{2}\right) p_{N L l o w}+\left(A \lambda_{h i \bar{L}}-\lambda_{h i \mid \overline{N L}}\right) F_{L \mid h i}\left(v_{2}\right) p_{N L \mid h i}$

We wish to show that at least one of the two preceding expressions is positive, for any value of $A$. Under the chosen claim screening thresholds, we have $F_{L \mid \text { low }}\left(v_{2}\right)=F_{N L \mid h i}\left(v_{1}\right)=0$. For the first expression to be positive, we must have $\lambda_{\text {low } \mid \overline{N L}}>A \lambda_{\text {low }} \bar{L}$. For the second to be positive, we need $\lambda_{h i \mid \overline{N L}}<A \lambda_{h i \mid}$. Because $\lambda_{\text {low } \mid \overline{N L}}>\lambda_{\text {low }} \mid \bar{L}$, the first expression is positive for $A<\lambda_{\text {low } \mid \overline{N L}} / \lambda_{\text {low } \mid \bar{L}}=A_{1}$. The second expression is positive for $A>\lambda_{h i \mid \overline{N L}} \mid \lambda_{h i \mid \bar{L}}=A_{2}$. Because $\lambda_{\text {low } \mid \overline{N L}}>\lambda_{\text {low } \mid \bar{L}}$, $A_{1}>1$ and $A_{2}<1$. Thus for $A<A_{2}$, only pro-defendant claim screening reduces cost, for $A>A_{1}$ only pro-plaintiff claim screening reduces cost and for $A_{2}<A<A_{1}$, both reduce cost.

Claim 3: Assume we have a signal $s$ with twice-differentiable conditional distributions $F_{N L \mid \text { low }}(s)$ and $F_{N L \mid h i}(s)$. Let their respective probability density functions be $f_{N L \mid l o w}(s)$ and $f_{N L \mid h i}(s)$. Assume we have an optimal (cost-minimizing) claim-screening policy $\left(t_{1}{ }^{*}, t_{2}{ }^{*}\right)$ satisfying $K / D<t_{1}{ }^{*}<t_{2}{ }^{*}<(1-K / D)$. Also assume that the second-order condition for a minimum is satisfied at $t_{1}{ }^{*}$ and $t_{2}{ }^{*}$, namely that $d^{2} E C_{C S} / d t_{1}{ }^{2}>0$ and $d^{2} E C_{C S} / d t_{2}{ }^{2}>0$. Then an increase in court costs implies an increase in $t_{1} *$ and a decrease in $t_{2}{ }^{*}$.

Proof: A necessary condition of the optimal claim-screening policy $\left(t_{1}^{*}, t_{2}{ }^{*}\right)$ is that the first-order conditions with respect to each threshold are zero when evaluated at $\left(t_{1}^{*}, t_{2}{ }^{*}\right)$. Define $G_{1}\left(t_{1}^{*}, K\right)$ and $G_{2}\left(t_{2}{ }^{*}, K\right)$ as: 
(9) $G_{1}\left(t_{1}^{*}, K\right)=\left.\frac{\partial E C_{C S}}{\partial t_{1}}\right|_{\left(t_{1}^{*}, t_{2}^{*}\right)}=\frac{\partial E C_{C S}\left(t_{1}^{*}, t_{2}^{*}, 0\right)}{\partial t_{1}}-\left(f_{N L \mid \text { ow }}\left(t_{1}^{*}\right) Z_{\text {low }}+f_{N L \mid h i}\left(t_{1}^{*}\right) Z_{h i}\right)=0$

(10) $G_{2}\left(t_{2}^{*}, K\right)=\left.\frac{\partial E C_{C S}}{\partial t_{2}}\right|_{\left(t_{1}^{*}, t_{2}^{*}\right)}=\frac{\partial E C_{C S}\left(t_{1}^{*}, t_{2}^{*}, 0\right)}{\partial t_{2}}+\left(f_{N L \mid l o w}\left(t_{2}^{*}\right) Z_{\text {low }}+f_{N L \mid h i}\left(t_{2}^{*}\right) Z_{h i}\right)=0$

Implicitly differentiating $G_{1}\left(t_{1}{ }^{*}, K\right)$ and $G_{2}\left(t_{2}{ }^{*}, K\right)$ and using the secondorder condition yields the desired results: $d t_{1} * / d K>0$ and $d t_{2} * / d K<$ 0 .

To gain some intuition on this result, consider equation (9). A small increase in the threshold for automatically dismissing cases means more cases will be dismissed. The first term in the three-term expression in equation (9) reflects the change in costs associated with an increased number of correctly and incorrectly overturned liability findings. This term is independent of court costs. The last two terms represent the additional benefits attributable to distorted payments in the presence of court costs among cases going to court. The existence of these additional benefits always means more cases should be screened out when court costs increase. The interpretation of equation (10) for the upper threshold is analogous. 